\title{
Sulfurated fertilizers enhance the microbial dissolution and release of arsenic from soils into groundwater by activating arsenate-respiring prokaryotes
}

\author{
X.C. Zeng, W.X. Shi, W.W. Wu \& S.G. Cheng \\ School of Environmental Studies, China University of Geosciences (Wuhan), Wuhan, Hubei, P.R. China
}

\begin{abstract}
This work aimed to investigate the activity and diversity of the dissimilatory arsenate-respiring prokaryotes (DARPs) in the paddy soils, and the effects of sulfate on the DARPs-catalyzed dissolution and release of arsenic and iron from paddy soils into aqueous phase. We collected arsenic-rich soils from a farmland region of the Xiantao city, Hubei, China. Microcosm assay was used to detect how DARPs catalyze the reduction, dissolution, and release of arsenic and iron from the soils, and how sulfate affects this microbial reaction. HPLCICP-MS technique was used to determine the arsenic and iron species. Quantitative PCR was used to measure the arsenate-respiring reductase gene abundances in the microcosms. We found that there are diverse DARPs in the indigenous microorganisms. Microcosm assays indicated that these DARPs efficiently promoted the mobilization, reduction and release of arsenic from soils under anaerobic condition. Remarkably, when sulfate was added into the reactions, the DARPs-mediated arsenic reduction and release were significantly increased. Agricultural activities may significantly promote arsenic-contamination in groundwater through increasing inputs of sulfate into paddy soils. It should be avoid overuses of sulfate fertilizers.
\end{abstract}

\section{INTRODUCTON}

Arsenic (As) is a highly toxic metalloid that is widely distributed in the environment. It can exist in organic or inorganic forms (Oremland et al., 2003; Zhu et al., 2014). It is present in more than 200 minerals, usually in combination with sulfur and metals (Kirk \& Holm, 2004; Smedley \& Kinniburgh, 2002; Ferguson et al., 1972). The most common arsenic-bearing mineral is arsenopyrite (Hao et al., 2014; Savage et al., 2004; Zhu et al., 2008). Arsenic typically occurs in four oxidation states: $-3,0,+3$ and +5 . The most dominant forms in arsenic-contaminated soils and water are As(III) (arsenite) and As(V) (arsenate). Arsenite is more soluble, mobile and toxic than arsenate. Arsenic compounds have been classified as a carcinogen to humans. Acute high-dose exposure to arsenic may cause severe systemic toxicity and death. Lowdose chronic exposure can result in cancers of various organs and tissues, hyperkeratosis, jaundice, neuropathy, diabetes mellitus, cardiovascular diseases, stroke, lung diseases, hepatotoxicity and other severe diseases (Zhu et al., 2014; Maguffin \& Kirk 2015; Singh et al., 2015)

Recently, it was found that high-arsenic groundwater exists in some areas in Jianghan Plain, China. A geochemical survey indicated that approximately $87 \%$ of the detected wells contained $10-2330 \mu \mathrm{g} \mathrm{L}^{-1}$ soluble arsenic. The sediments from the detected sites contained $10.73-136.72 \mathrm{mg} \mathrm{L}^{-1}$ adsorbed or mineral arsenic (Gan et al., 2014). More recently, we found that the microbial communities from deep sediments, instead of shallow soils, efficiently catalyzed the reduction, dissolution and release of arsenic from insoluble phase into groundwater (Chen et al., 2017). In this study, we aimed to explore how agricultural activities affect the arsenic mobilization and release from shallow soils into groundwater in Jianghan Plain. Because Jianghan Plain is one of the most important food grain production districts in China, sulfate fertilizers are widely used as essential $\mathrm{S}$ nutrients for the growth of crops. This significantly increased the sulfate contamination, suggesting that sulfate is one of the major environmental factors in the soils of this region. We found that sulfate has great effects on the indigenous microbial communities-catalyzed arsenic dissolution, reduction and release of arsenic from the paddy soils into groundwater. This finding provided direct evidence that anthropogenic agricultural activity significantly enhanced the arsenic contamination in groundwater.

\section{METHODS/EXPERIMENTAL}

We collected arsenic-rich soils from a farmland region of the Xiantao city, Hubei, China. Microcosm assay was used to detect how DARPs catalyze the reduction, dissolution, and release of arsenic and iron from the soils, and how sulfate affects this microbial reaction. HPLC-ICP-MS technique was used to determine the arsenic and iron species. Quantitative PCR was used to measure the arsenate-respiring reductase gene abundances in the microcosms. 

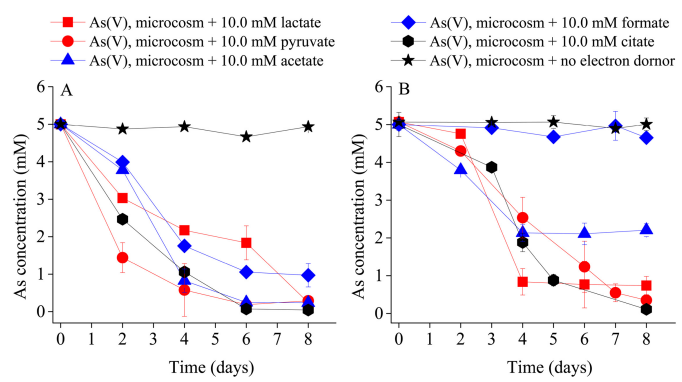

Figure 1. Arsenate-respiring reduction activities of the microbial communities from the sediment samples. Arsenate-respiring curve of the microcosm from the depth of $1.6 \mathrm{~m} \mathrm{(A)} \mathrm{and} 4.6 \mathrm{~m} \mathrm{(B).} \mathrm{Active} \mathrm{microcosms} \mathrm{of} \mathrm{the} \mathrm{two}$ samples were inoculated into the MM medium amended with $5.0 \mathrm{mM} \mathrm{As}(\mathrm{V})$ as the sole electron acceptor and $10.0 \mathrm{mM}$ lactate, formate, pyruvate, acetate or citrate as a electron donor

\section{RESULTS AND DISCUSSION}

\subsection{Arsenate-respiring activities of the microorganisms in the soils}

Microcosm assay was used to detect the arsenaterespiring activity of the microbial communities from the soils. The results showed that the arsenate-respiring activities were detectable in all of the two samples that were supplemented with different electron donors, and no significant arsenate-reducing activities were detected in the absence of external electron donors (Fig. 1).

\subsection{Unique diversity of the arsenate-respiring reductase genes from the soils}

To understand the molecular basis of the arsenaterespiring activities of the soils, we explored the molecular diversity of the arsenate-respiring reductase genes present in the microbial communities of the soils by cloning, sequencing and analyzing the arr $A$ marker sequence. We identified 27 novel arrA genes. Their encoded Arr proteins were referred to as M1 to M18 (from $1.6 \mathrm{~m}$ ), and $\mathrm{N} 1$ to $\mathrm{N} 8$ (from $4.6 \mathrm{~m}$ ). The amino acid sequences of these Arr proteins were each used as queries to search against the GenBank database using the BLAST sever. We found that the Arr proteins from the soils share $71-89 \%$ sequence identities with other known microbial Arr proteins, suggesting that a lot of new or new-type DARPs were present in the soils (Fig. 2).

\subsection{Microbial dissolution and release of As(III) and $\mathrm{Fe}(\mathrm{II})$ from the shallow soils}

To determine whether the microbial communities in the shallow soils are capable of catalyzing the arsenic

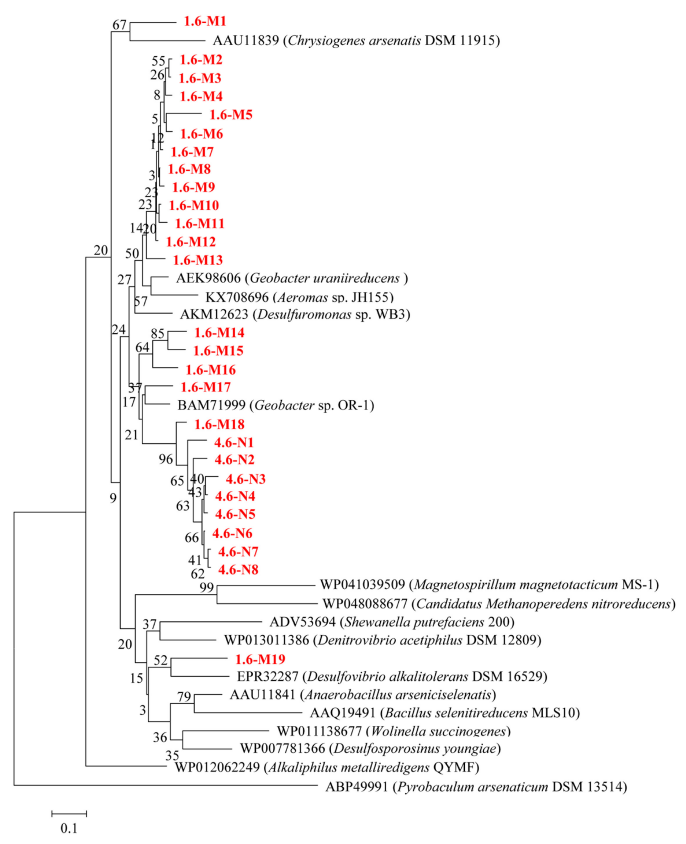

Figure 2. Phylogenetic analysis of arsenate-respiring reductases from the high-arsenic shallow sediments of Jianghan Plain.
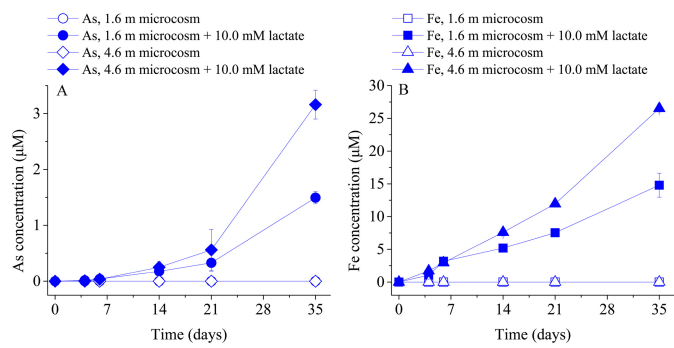

Figure 3. The mobilization, reduction and release of insoluble arsenic and iron catalyzed by microbial communities from the sediment samples using microcosm assay technique. The As(III) (A) and Fe(II) (B) release curves were achieved using the microcosms of the samples from the depth of $1.6 \mathrm{~m}$ and $4.6 \mathrm{~m}$. Active microcosms of the two samples were prepared by inoculating each of the samples into the synthetic groundwater supplemented with $10.0 \mathrm{mM}$ lactate.

release from insoluble phase, we conducted arsenic release assay using the soil samples under anaerobic condition.

These results suggest that the microorganisms in the soils of the depths 1.6 and $4.6 \mathrm{~m}$ significantly catalyzed the dissolution and release of arsenic and iron from the soils into aqueous phase, and the amount of the released iron was greater than that of the release arsenic. These data also indicated that there were more arsenic and iron released from the soils of $4.6 \mathrm{~m}$ than from those of $1.6 \mathrm{~m}$ (Fig. 3). 

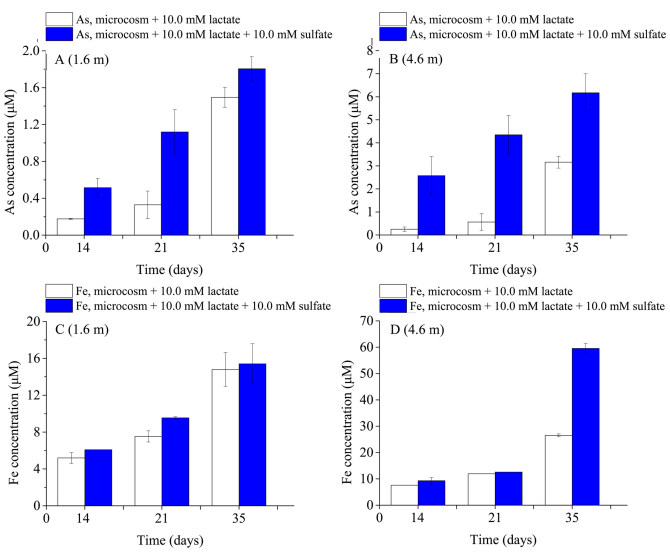

Figure 4. The mobilization, reduction and release of insoluble arsenic and iron catalyzed by microbial communities from the sediment samples in the presence of $10.0 \mathrm{mM}$ sulfate or without sulfate using microcosm assay technique. The As(III) and $\mathrm{Fe}$ (II) release curves were achieved using the microcosms of the samples from the depth of $1.6 \mathrm{~m}(\mathrm{~A}, \mathrm{C})$ and $4.6 \mathrm{~m}(\mathrm{~B}$, D). Active microcosms of the two samples were prepared by inoculating each of the samples into the synthetic groundwater supplemented with $10.0 \mathrm{mM}$ lactate and $10.0 \mathrm{mM}$ sulfate or without sulfate.

\subsection{Sulfate significantly enhanced the microorganisms-mediated release of arsenic and iron}

These results suggested that sulfate significantly enhanced the microorganisms-catalyzed dissolution, reduction and release of arsenic and iron from the soil phase (Fig. 4).

\subsection{Structures of the microbial communities from the soils}

To better understand the microbial basis of the observations, we analyzed the structures of the microbial communities from the soils using illumine high-throughout paired-end sequencing technique. We identified 39 phyla of bacteria.

As shown in Figure 5, the microbial community from the depth of $1.6 \mathrm{~m}$ consisted of Chloroflexi (38.16\% of the total microorganisms), Proteobacteria (25.07\%), Acidobacteria (10.00\%), Gemmatimonadetes (5.35\%), Latescibacteria (3.11\%), Aminicenantes (2.43\%), Nitrospirae (1.38\%), Actionbacteria (1.34\%), Firmicutes (1.00\%), Bacteroidetes $(0.35 \%)$, Spirochaetae $(0.34 \%)$, and other microorganisms with less abundance; the microorganisms from the depth of $4.6 \mathrm{~m}$ included Proteobacteria (50.77\%), Chloroflexi (15.38\%), Firmicutes (14.24\%), Nitrospirae (7.11\%), Bacteroidetes (6.17\%), Aminicenantes (2.97\%), Actionbacteria (2.51\%), Acidobacteria (1.94\%), Spirochaetae $(1.70 \%)$, candidate division Gal $15(1.53 \%)$, Gemmatimonadetes $(0.43 \%)$, Latescibacteria $(0.30 \%)$, and other less abundant microorganisms. This suggests that the microbial community structure from the depth

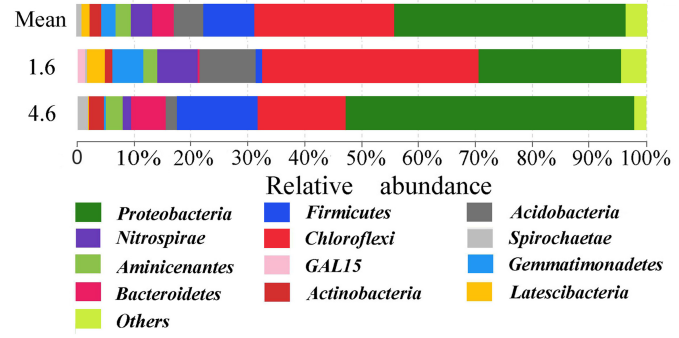

Figure 5. Analysis of the microbial community compositions of the sediment samples at phylum level from the Jianghan Plain.

$1.6 \mathrm{~m}$ significantly differs from that from the depth of $4.6 \mathrm{~m}$.

\section{CONCLUSIONS}

This study aimed to explore how arsenic was released from soil phase into groundwater, and how sulfate affects this bioprocess in Jianghan Plain, China. We found that a large diversity of DARPs are present in the shallow soils from the depths of 1.6 and $4.6 \mathrm{~m}$. Microcosm assays indicated that the microbial communities significantly catalyzed the dissolution, reduction and release of arsenic and iron from the soils into aqueous phase. It is interesting to see that addition of $10.0 \mathrm{mM}$ sulfate into the microcosms led to a significant increase of the microorganisms-mediated release of arsenic and iron from the soils. Quantitative PCR analysis for the functional gene abundances suggested that the sulfate-induced increase of microbial release of arsenic and iron was attributed to the significant enhancement of the DARP growth by sulfate. These results suggested that agricultural uses of sulfate fertilizers enhanced arsenic contamination in groundwater. The findings of this study gained new insight into the mechanisms by which the arsenic-contaminated groundwater was formed, and gave direct evidence that agricultural activities may enhance the arsenic contamination in groundwater.

\section{ACKNOWLEDGEMENTS}

This work was financially supported by the National Natural Science Foundation of China (grants no. 41472219, 41072181, 41272257 and 41521001).

\section{REFERENCES}

Chen, X.M., Zeng, X.C., Wang, J.N., Deng, Y.M., Ma, T., E.G.J., Mu, Y., Yang, Y., Li, H. \& Wang, Y.X. 2017. Microbial communities involved in arsenic mobilization and release from the deep sediments into groundwater in Jianghan plain, Central China. Sci. Total Environ. 579: 989-999.

Ferguson, J. F. \& Gavis, J. 1972. A review of the arsenic cycle in natural waters. Water Res. 6: 1259-1274. 
Gan, Y.Q., Wang, Y.X., Duan, Y.H., Deng, Y.M., Guo, X.X. \& Ding, X.F. 2014. Hydrogeochemistry and arsenic contamination of groundwater in the Jianghan Plain, central China. J. Geochem. Explor. 138: 81-93.

Hao, T.W., Xiang, P.Y., Mackey, H.R., Chi, K., Lu, H., Chui, H.K., van Loosdrecht, M.C.M. \& Chen, G.H. 2014. A review of biological sulfate conversions in wastewater treatment. Water Res. 65: 1-21.

Kirk, M.F., Holm, T.R., Park, J., Jin, Q.S., Sanford, R.A., Fouke, B.W. \& Bethke, C.M. 2004. Bacterial sulfate reduction limits natural arsenic contamination in groundwater. Geology 32: 953-956.

Maguffin, S.C., Kirk, M.F., Daigle, A.R., Hinkle, S.R. \& Jin, Q.S. 2015. Substantial contribution of biomethylation to aquifer arsenic cycling. Nat. Geosci. 8: 290-293.

Oremland, R.S. \& Stolz, J.F. 2003. The ecology of arsenic. Science 300(5621): 939-944.
Savage, K.S., Tingle, T.N., O’Day, P.A., Waychunas, G.A. \& Bird, D.K. 2004. Arsenic speciation in pyrite and secondary weathering phases, Mother Lode Gold District, Tuolumne County, California. Appl. Geochem. 15(8): 1219-1244.

Smedley, P.L. \& Kinniburgh, D.G. 2002. A review of the sources, behavior and distribution of arsenic in natural waters. Appl. Geochem. 17: 517-568.

Zhu, W., Young, L.Y., Yee, N., Serfes, M., Rhine, E.D. \& Reinfelder, J.R. 2008. Sulfide-driven arsenic mobilization from arsenopyrite and black shale pyrite. Geochim. Cosmochim. Acta. 72: 5243-5250.

Zhu, Y.G., Yoshinaga, M., Zhao, F.J. \& Rosen, B.P. 2014. Earth Abides Arsenic Biotransformations. Ann. Rev. Earth Planet. Sci. 42: 443-467. 